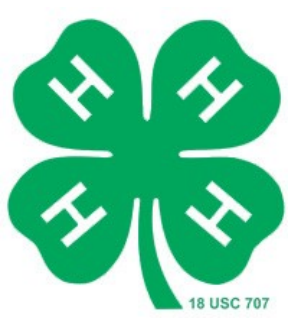

\title{
Selecting a Name for a 4-H Club ${ }^{1}$
}

members might shy away from joining just because of a misleading name; have youth consider whether the name will grow as the $4-\mathrm{H}$ members grow. To maintain a positive image for the entire 4-H program, club names should neither shock nor confuse the public. Trendy names rarely stand the test of time.

\section{Examples:}

"The Sewing Susans" or "The Pony Girls 4-H Club" would not be allowed as a 4-H Club name as the name obviously discriminates against boys; the name chosen must be appropriate to either sex. “The Nimble Thimbles 4-H Club” might be a better idea. But, make sure such a “cute” name wouldn't be a turn-off to any members or potential members. Teens are particularly sensitive to cute names that may be appreciated by younger kids.

For a 4-H gardening club: "The Dirty Hands" would not be as appropriate as "The Green Thumbs 4-H Gardening Club" or "The GrowKids 4-H Club.”

\section{Making the Decision}

The decision making process for selecting a club name can be handled by following a few basic steps. Just remember, this process may take some time for young people, depending upon their age. So, help them create a process to involve all, even if it takes more than the first or second club meeting to finalize their choice.

\section{Naming a Club can be FUN!}

Creative or cute names for 4-H clubs are fine. But consider whether any potential club

\footnotetext{
This document is 4-H S FS101.7 one of a series of the Florida 4-H Program, Florida Cooperative Extension Service, Institute of Food and Agricultural Sciences, University of Florida. This material is based upon work supported by the Cooperative Research, Education, and Extension Service, US Department of Agriculture, and K-State Research and Extension, Kansas State University, under special project number 99-EYAR-1-0747. This 4-H 101 Handbook was developed by the 4-H 101 Design Team chaired by Andrea Hutson, USDA/Army Youth Development Project, CSREES/Virginia Tech University. It was adapted for Florida by Marilyn N. Norman and Joy C. Jordan, State 4-H Program. Published May 2006. Please visit the 4-H Website at http://4h.ifas.ufl.edu

${ }^{2}$ Marilyn Norman, Associate Professor in Family Youth and Community Sciences, and State 4-H Program Leader, and Joy C. Jordan, Associate Professor in Family, Youth and Community Sciences, Institute of Food and Agricultural Sciences, University of Florida, Gainesville.
} 
Follow these basic decision-making steps to help club members learn about their first group decision:

\section{STEP 1: Identify the Problem:}

Selecting a 4-H Club name that is nondiscriminatory. Using the above examples, help younger members understand the criteria.

\section{STEP 2. Brainstorm Solutions:}

Think of many possible names. Let the members be creative in the way they generate or solicit club name possibilities. If the group is small, it might use simple brainstorming methods. If the group is large, the group might create a ballot name box where youth and parents make suggestions, a committee reviews, tallies, and makes a list to have membership vote. Whatever works best to involve all members.

\section{STEP 3. Think Through Each Solution:}

Consider whether the names suggested meet the criteria. Again, depending upon the size of the group this may be done by total club membership or small committee at first.

\section{STEP 4. Select the Most Appropriate Solution:}

4-H members should reach a consensus or use a vote by majority rule to make their decision. If this isn't practical, especially if the club is large, the club can simply accept or vote on a committee's recommendations.

\section{In Summary}

Most inappropriate choices become obvious. Just beware of the not so obvious possibilities! Therefore, when selecting a club name, think about it carefully, be creative, and use a little common sense. To avoid confusion, try not to select a name currently being used by another club in the county. When in doubt about a duplication or acceptance of a name, contact the county 4-H office for “approval” or suggestions.

Adapted From: University of New Hampshire Cooperative Extension, A Guide for Leaders, 2004 and New Jersey 4-H Leader Training Series, Rutgers., The State University of New Jersey, 1994. 